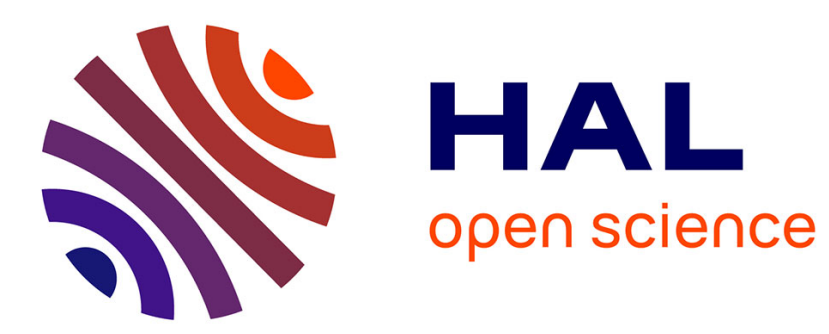

\title{
Vitrification and Crystallization of Organic Liquids Confined to Nanoscale Pores
}

\author{
Catheryn L Jackson, Gregory B. Mckenna
}

\section{To cite this version:}

Catheryn L Jackson, Gregory B. Mckenna. Vitrification and Crystallization of Organic Liquids Confined to Nanoscale Pores. Chemistry of Materials, 1996, 8 (8), pp.2128-2137. 10.1021/cm9601188. hal-02557809

\section{HAL Id: hal-02557809 \\ https://hal.science/hal-02557809}

Submitted on 29 Apr 2020

HAL is a multi-disciplinary open access archive for the deposit and dissemination of scientific research documents, whether they are published or not. The documents may come from teaching and research institutions in France or abroad, or from public or private research centers.
L'archive ouverte pluridisciplinaire HAL, est destinée au dépôt et à la diffusion de documents scientifiques de niveau recherche, publiés ou non, émanant des établissements d'enseignement et de recherche français ou étrangers, des laboratoires publics ou privés. 


\title{
Vitrification and Crystallization of Organic Liquids Confined to Nanoscale Pores
}

\author{
Catheryn L. J ackson* and Gregory B. McKenna \\ Polymers Division, The National Institute of Standards and Technol ogy, \\ Gaithersburg, Maryland 20899
}

Received February 9, 1996. Revised Manuscript Received April 11, $1996^{\otimes}$

\begin{abstract}
The effect of finite size on the solidification of o-terphenyl and benzyl alcohol confined in model controlled pore glass (CPG) materials is described. These two organic liquids form either amorphous glasses or crystalline solids in the bulk upon cooling, depending on the rate of cooling and other factors. The solidification behavior of the liquid in the pores was studied as a function of pore diameter $(4-73 \mathrm{~nm})$, chemical surface treatment of the CPG and the degree of pore filling, by differential scanning calorimetry (DSC). We observe that the glass transition, $T_{g}$, shifts to a lower temperature as pore size decreases. This shift is independent of the degree of pore filling for both o-terphenyl and benzyl alcohol, suggesting that a reduction in bulk density or a negative pressure effect is not the cause of the observed shift. The crystallization behavior of o-terphenyl and benzyl alcohol is also altered by confinement and strongly depends on the pore size and degree of pore filling.
\end{abstract}

\section{Introduction}

When a liquid is cooled, a crystalline solid or an amorphous glass may form depending on the nature of the liquid and the conditions under which the solidification occurs. ${ }^{1-3}$ The degree of supercooling the liquid can sustain upon lowering the temperature controls the ultimate morphology and is strongly influenced by finite-size effects. The finite-size effects are related to the formation of a critical nucleus size for crystallization, the increased surface-to-volume ratio of small crystals, the wetting properties of the liquid on the substrate, the effect of finite size on the dynamics of the liquid, and other factors. Finite-size effects are often imposed by a matrix with small pores, such as porous glass, silica gel, a zeol ite, or a polymer gel, but may also arise in free-standing geometries such as thin polymeric films. The goal of finite-size studies is often fundamental in nature, for example, to keep a liquid in a supercooled state to promote and study gl ass formation ${ }^{4-6}$ or to study the shift of the critical temperature in molecular fluids and critical mixtures. ${ }^{7-9}$ Molecular clusters of metal atoms prepared by evaporation techniques al so exhibit dramatic finite-size effects. ${ }^{10}$

When the size of crystals is in the nanometer range, the crystalline melting temperature is reduced compared to the bulk melting point. This effect is due to the increase in free energy as the surface area to volume ratio of the crystal becomes significant. The Gibbs-

$\otimes$ Abstract published in Advance ACS Abstracts, J uly 15, 1996.

(1) Kauzman, W. Chem. Rev. 1948, 43, 219.

(2) Turnbull, D. Cont. Phys. 1969, 10, 473.

(3) Turnbull, D.; Cohen, M. H. J . Chem. Phys. 1958, 29, 1049

(4) MacFarlane, D. R.; Angell, C. A. J . Phys. Chem. 1982, 86, 1927.

(5) Teixeira, J.; Alba-Simionesco, C.; Angell, C. A. Prog. Colloid Polym. Sci. 1991, 84, 117.

(6) Alba, C.; Busse, L. E.; List, D. J .; Angell, C. A. J . Chem. Phys. 1990, 92, 617.

(7) Tell, J . L.; Maris, H. J . Phys. Rev. B 1983, 28, 5122.

(8) Warnock, J .; Awschalom, D. D.; Shafer, M. W. Phys. Rev. Lett. 1986, 57, 1753.

(9) Molz, E.; Wong, A. P. Y.; Chan, M. H. W.; Beamish, J . R. Phys. Rev. B 1993, 48, 5741.

(10) Buffat, Ph.; Borel, J .-P. Phys. Rev. A 1978, 13, 2287.
Thomson equation predicts that the melting point depression, $\Delta T_{m}$, for a small cylindrical crystal of diameter, $d$, is given by

$$
\Delta T_{m}=T_{m}-T_{m}(d)=4 \sigma_{s l} T_{m} /\left(d \Delta H_{f} \rho_{s}\right)
$$

where $T_{m}$ is the normal (bulk) melting point, $T_{m}(d)$ is the melting point of crystals of size $d, \sigma_{\mathrm{sl}}$ is the surface energy of the solid-liquid interface, $\Delta \mathrm{H}_{\mathrm{f}}$ is the bulk enthalpy of fusion (per gram of material), and $\rho_{\mathrm{s}}$ is the density of the solid. ${ }^{11}$ Equation 1 assumes that the crystal size is sufficient so that the material retains it bulk values of $\Delta \mathrm{H}_{\mathrm{f}}$ and $\rho_{\mathrm{s}}$. Many reports exist which confirm the Gibbs-Thomson equation for the melting points of small crystals. ${ }^{12-14}$ These reports often extend even beyond the range where such a continuum model is expected to be valid. ${ }^{15}$

We previously made a systematic investigation of the finite-size effect on the melting temperatures for small organic crystals ${ }^{13}$ using controlled pore glass (CPG) materials with narrow pore-size distributions and a wide range of pore sizes. The pore diameters studied were in the range $4-73 \mathrm{~nm}$, and the measurements were made by differential scanning calorimetry (DSC). The melting temperature, $T_{m}(d)$, was found to decrease linearly with reciprocal pore size, in agreement with eq 1. Although the surface of the glass was treated with hexamethyldisilazane to encourage wetting by nonpolar organic liquids, the degree of pore filling, depicted schematically in Figure 1, was found to have a minimal effect on the shift in $T_{m}$. This observation suggested that the nonpolar organic liquids tend to form "plugs" (Figure 1a) rather than first wet the interior surfaces

(11) Defay, R.; Prigogine, I.; Bellemans, A.; Everett, D. H. Surface Tension and Adsorption; Wiley: New York, 1966.

(12) Rennie, G. K.; Clifford, J . J . Chem. Soc., Faraday Trans. 1 $1977,73,680$.

(13) J ackson, C. L.; Mckenna, G. B. J . Chem. Phys. 1990, 93, 9002.

(14) Unruh, K. M.; Huber, T. E.; Huber, C. A. Phys. Rev. B 1993, 48,9021 .

(15) Reiss, H.; Koper, G. J . M. J . Phys. Chem. 1995, 99, 7837. 


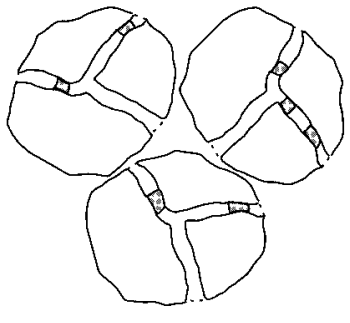

(a)

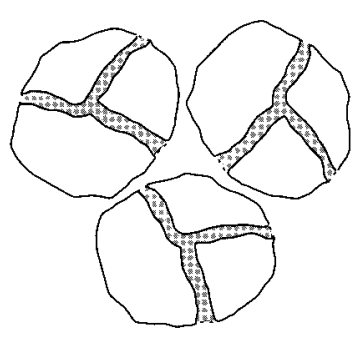

(c)

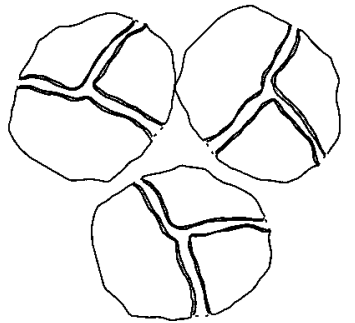

(b)

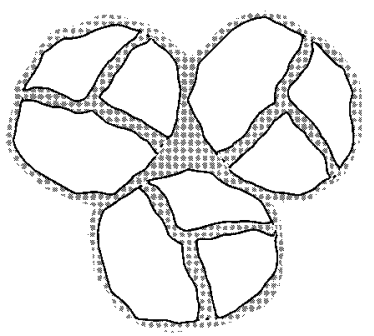

(d)
Figure 1. Schematic illustration of pore filling in CPG materials, where three small grains of porous glass are grouped together for illustrative purposes. As the CPG comes into contact with a liquid and its vapor, (a) poor wetting-the liquid enters the smallest diameter pores and form "plugs", (b) good wetting-the liquid coats the interior surfaces completely, before forming a "plug" (c) the cavities are filled to maximum capacity, and (d) the outer surfaces and interstitial space between the grains are wet. The liquid is designated as the shaded region and open pore space is unshaded. Notethat the pores are actually much smaller (from 4 to $73 \mathrm{~nm}$, see Table 1) than depicted with respect to the CPG grain size (100 $\mu \mathrm{m})$ and the interstitial space.

of the glass (Figure $1 \mathrm{~b}$ ). As more liquid is added, the pores are filled to capacity (Figure 1C) and eventually to a condition of overfilling (Figure 1d), where both pore liquid and excess bulk liquid coexist. For capillary condensation to occur the meniscus of the liquid must be concave, which effectively lowers the vapor pressure of the liquid in the pores relative to the bulk. The smaller the pore diameter the lower the vapor pressure, so the smallest diameter pores tend to fill first. For water in untreated CPG, the behavior depicted in Figure $1 b$ has been reported at low pore fillings and a very low contact angle is expected. ${ }^{12}$ For liquids that do not wet the surface completely during the filling of the pores, however, a nonzero value of the contact angle increases the radius of curvature of the meniscus. ${ }^{11}$ Because the nonpolar organic liquids studied here do not wet the glass but form "plugs", a relatively flat menicus is depicted in Figure 1a. This observation has important implications for the solidification process of the liquid.

In this work, the effect of finite size on both glass formation and crystallization was studied simultaneously for two organic compounds, o-terphenyl and benzyl alcohol. The liquids were imbibed in CPG materials of narrow pore size distribution with pore diameters in the range of 4-73 nm, and the measurements were made by DSC. We have studied the competition between glass formation and crystallization as the pore size, degree of pore filling, and the surface treatment are varied. We previously measured the glass transition temperature of these compounds as a function of pore diameter, $T_{g}(d)^{16}$ when the pores were completely filled (Figure 1c). The observed behavior could not be explained as readily as the shift in $T_{m}$, however, and is further explored in this report. Under some experimental conditions, crystallization is observed for benzyl alcohol, and the origin and type of nucleation for crystals formed within the pores can be described. For o-terphenyl, crystallization of the pore liquid was not observed under most of the experimental conditions studied, except in the CPG material with the largest pore diameter $(73 \mathrm{~nm})$. A discussion of the effect of confined geometry on the melting temperature and glass transition behavior is made with regard to the ease of formation of a glass from an organic liquid and the thermodynamic stability of crystalline solids. The experimental data providefurther information about the mechanism by which the $T_{g}$ is shifted when a liquid is confined.

Finite-size effects have importance in both theoretical and experimental research. The theoretical interest is centered around the fundamental nature of solids, 17,18 capillary condensation in liquids, 15,19 the dynamical theories of the liquid-glass transition ${ }^{20,21}$ and the role of free surfaces on the structure of polymeric materials. ${ }^{22,23}$ The effect of a confined geometry has practical rel evance to the areas of polymer thin films, ${ }^{24-27}$ nanostructured materials, ${ }^{28-32}$ and tribology. ${ }^{33,34}$ In the case of thin films of an amorphous homopolymer, it has been shown that finite-size effects must be carefully distinguished from effects due to a strong affinity of the polymer for the substrate. ${ }^{32,35,36}$ Spin-coating techniques are often used to prepare thin polymer films and can produce nonequilibrium conformations if the film cannot be properly annealed because of substrate dewetting. More complicated systems have also been studied, such as thin films of phase-separated polymer blends ${ }^{37,38}$ where preferential adsorption of one polymer to the substrate or air interface may occur. Preferential adsorption alters the composition of the blend and must

(16) J ackson, C. L.; McKenna, G. B. J . Non-Cryst. Solids 1991, 131133, 221.

(17) Wales, D. J .; Berry, R. S. J . Chem. Phys. 1990, 92, 4473.

(18) Lobe, B.; Baschnagel, J . J . Chem. Phys. 1994, 101, 1616.

(19) Cracknell, R. F.; Gubbins, K. E.; Maddox, M.; Nicholson, D. Acc. Chem. Res. 1995, 28, 281.

(20) Fredrickson, G. H. Annu. Rev. Phys. Chem. 1988, 39, 149.

(21) Ray, P.; Binder, K. Europhys. Lett. 1994, 27, 53.

(22) Mayes, A. M. Macromolecules 1994, 27, 3114.

(23) Couchman, P. R.; Karasz, F. E.J . Polym. Sci., Part B: Polym. Phys. 1977, 15, 1037.

(24) Keddie, J . L.; J ones, R. A. L.; Cory, R. A. Europhys. Lett. 1994 $27,59$.

(25) Reiter, G. Macromolecules 1994, 27, 3046.

(26) Beaucage, G.; Composto, R.; Stein, R. S. J . Polym. Sci., Part B: Polym. Phys. 1993, 31, 319.

(27) Russell, T. P.; Menelle, A.; Anastasiadis, S. H.; Satija, S. K.; Majkrzak, C. F. Macromolecules 1991, 24, 6263.

(28) Service, R. F. Science 1995, 267, 327.

(29) Röder, H.; Hahn, E.; Brune, H.; Bucher, J .-P.; Kern, K. Nature 1993, 366, 141.

(30) Metiu, H. Nature 1993, 366, 111.

(31) Meijer, H. E. H.; van der Sanden, M. C. M. 9th International Conference on Deformation, Yield and Fracture of Polymers; The Institute of Materials: London, 1994; $\mathrm{p}$ 7/1.

(32) Vaia, R.; Sauer, B. B.; Tse, O.; Giannelis, E. P. J . Polym. Sci., Polym. Phys. Ed., submitted.

(33) Klein, J .; Kumacheva, E.; Mahalu, D.; Perahia, D.; F etters, L. J. Nature 1994, 370, 634.

(34) Granick, S. Science 1994, 253, 1374.

(35) Keddie, J . L.; J ones, R. A. L.; Cory, R. A. Faraday Discuss. 1994, 98, 219.

(36) Wallace, W. E.; van Zanten, J . H.; Wu, W. L. Phys. Rev. E 1995, 52, R3329.

(37) Reich, S.; Cohen, Y.J . Polym. Sci., Polym. Phys. Ed. 1981, 19, 1255.

(38) Nesterov, A.; Horichko, V.; Lipatov, Y. Makromol. Chem., Rapid Comm. 1991, 12, 571. 
Table 1. Controlled Pore Glass Properties

\begin{tabular}{cccc}
\hline $\begin{array}{c}\text { mean } \\
\text { diameter, }\end{array}$ & nm \\
$\pm \%{ }^{b}$ & $\begin{array}{c}\text { surface } \\
\text { areac }^{c}\left(\mathrm{~m}^{2} / \mathrm{g}\right)\end{array}$ & $\begin{array}{c}\text { pore } \\
\text { volume }^{\mathrm{a}}\left(\mathrm{cm}^{3} / \mathrm{g}\right)\end{array}$ \\
\hline 4.0 & 12.8 & 144 & 0.13 \\
8.5 & 13.5 & 175 & 0.59 \\
15.6 & 5.7 & 166 & 0.90 \\
25.5 & 3.7 & 95.5 & 0.96 \\
73.0 & 8.6 & 33.9 & 0.98
\end{tabular}

a Determined by mercury intrusion method. b $90 \%$ of the pore diameters are withing this range. ${ }^{\mathrm{C}}$ Determined by the nitrogen adsorption method (BET equation).

be accounted for before the effect of finite-size on the phase separation temperature can be ascertained. In systems such as microphase-separated block copolymers, ${ }^{39-42}$ thin films are not necessary to observe finitesize effects on $T_{g}$ since domain sizes in the nanometer range are common, but diluent effects can produce shifts in $T_{g}$, as well. In deformed polymers, the observation that craze fibrils $(\sim 9 \mathrm{~nm}$ in diameter) coalesce at temperatures up to $100{ }^{\circ} \mathrm{C}$ lower than the bulk $T_{g}$, resulting in healing of the craze, ${ }^{43}$ has been attributed to a finite-size effect. For small molecule liquids, especially water, the study and prevention of freezing ${ }^{4-46}$ has broad applications since porous materials have widespread use in construction. In addition, finite-size effects are important in technological applications such as catalysts, membranes, and control led release drugs, which utilize the unique properties of porous materials.

\section{Experimental Section}

The origin and preparation of the CPG materials used in this study are described in detail elsewhere. ${ }^{13}$ The CPG is a white, free-flowing powder of 120/200 mesh size. The mean pore diameter, the percentage of pores that are within $90 \%$ of this size, and the pore volume for each CPG were determined by mercury intrusion and are given in Table 1 . The surface area of the glass is also given in Table 1 , as determined by nitrogen adsorption using the Brunauer-Emmett-Teller (BET) equation. The surface of the CPG was derivatized with hexamethyldisilazane, after cleaning thoroughly with hot nitric acid, to convert the surface hydroxyl groups to trimethylsilyl groups. This treatment makes the glass more hydrophobic and promotes wetting by organic liquids. Some freshly d eaned but untreated glass was also used to analyze the effect of the surface treatment. The CPGs were stored in a desiccator when not in use.

The o-terphenyl (1,2-diphenylbenzene) used in this study was purified as described by Chang et al., ${ }^{47}$ to $99.99 \%$. Anhydrous benzyl alcohol ( $\alpha$-hydroxytoluene) was obtained from Aldrich Chemical Co. ${ }^{48}$ (SureSeal bottle of $99.8 \%$ purity) and used without further purification. It was stored in the original bottle and removed with a syringe to prevent contamination.

A Perkin-Elmer differential scanning calorimeter (DSC-2) was specially modified for low-temperature studies and had a lower temperature limit of $140 \mathrm{~K}$. Calibration of the DSC was

(39) Bares, J. Macromolecules 1975, 8, 244.

(40) Krause, S.; Lu, Z.; I skandar, M. Macromolecules 1982, 15, 1076.

(41) Lu, X.; Weiss, R. A. Macromolecules 1993, 26, 3615.

(42) Gaur, U.; Wunderlich, B. Macromolecules 1980, 13, 1618.

(43) Berger, L. L.; Sauer, B. B. Macromolecules 1991, 24, 2096.

(44) Handa, Y. P.; Zakrzewski, M.; Fairbridge, C. J . Phys. Chem. 1992, 96, 8594

(45) Pfeifer, H.; Oehme, W.; Siegel, H. Z. Phys. Chem. N. F. 1987, 152, 215.

(46) Dash, J. G.; Fu, H.; Wettlaufer, J . S. Rep. Prog. Phys. 1995 $58,115$.

(47) Chang, S. S.; Bestul, A. B. J . Chem. Phys. 1972, 56, 503.

(48) Certain commercial companies are named in order to specify adequately the experimental procedure. This in no way implies endorsement or recommendation by NIST. done using the melting points of several pure organic materials, as described elsewhere. ${ }^{13}$ The sample pans used were large volume, stainless steel pans (Perkin-Elmer ${ }^{48}$ No. 03190218) sealed with an o-ring to prevent liquid loss. The sample pans were preweighed and the CPG and organic material were then weighed into the pan, so that quantitative calorimetric measurements could be made. The CPG/benzyl al cohol mixtures were equilibrated overnight at room temperature while the CPG/o-terphenyl mixtures were heated at about $370 \mathrm{~K}$ for a few hours to equilibrate. Before analysis the samples were reweighed to ensure that the pans were sealed properly. A few pans showed a large weight loss due to improper sealing and were discarded.

The experimental conditions were chosen to prevent annealing (volume recovery) of the glass while heating. Prevention of annealing is generally assured by using a heating rate which is greater than or equal to the cooling rate used to prepare the glass. ${ }^{49}$ In addition, because slower rates make $\mathrm{T}_{\mathrm{g}}$ more difficult to detect by DSC and faster rates are undesi rable due to thermal lag effects, we carefully balanced these considerations to optimize the experimental conditions. The quenched glass of o-terphenyl was prepared by heating to above the normal melting point $(329 \mathrm{~K})$ to $350 \mathrm{~K}$ for $15 \mathrm{~min}$ and then cooling at $10 \mathrm{~K} / \mathrm{min}$ to $190 \mathrm{~K}$. The $\mathrm{T}_{\mathrm{g}}$ and heat capacity, $\Delta C_{p}$, were then measured during heating at 10 $\mathrm{K} / \mathrm{min}$. For the benzyl alcohol, which is a liquid at room temperature, the glass was prepared by cooling at $5 \mathrm{~K} / \mathrm{min}$ to $140 \mathrm{~K}$ and then reheating at the same rate to obtain the $\mathrm{T}_{\mathrm{g}}$. The slower rate was used for benzyl alcohol because for instrumental reasons, the faster rate of $10 \mathrm{~K} / \mathrm{min}$ interfered with the lower temperature limit of the scan $(140 \mathrm{~K})$ where the transition is observed.

The weight of both the organic and inorganic material in each pan is known, so that the pore fullness can be calculated using the pore volumes given in Table 1 . The concentrations are reported in $\mathrm{cm}^{3}$ of liquid/gram of CPG, calculated using the liquid densities of o-terphenyl and benzyl alcohol (at room temperature). The bulk enthalpy of the melting peak at the normal melting point can then be used to calculate the amount of excess material present. The value of the internal pore volume is easily verified by subtracting the amount of excess pore material from the total amount of organic in the pan. In all cases, the values obtained were within $5 \%$ of the numbers given in Table 1. The experimental DSC curves were normalized by dividing by the total weight of the organic material. This allows a direct comparison of the change in the heat capacity at $\mathrm{T}_{\mathrm{g}}$. When the excess pore liquid has crystallized and the normal melting peak is observed, the normalized curves are scaled as indicated in the figure caption.

Both the midpoint and onset values of $\mathrm{T}_{\mathrm{g}}$ are reported to estimate the breadth of the transition region. These values were calculated by the DSC-2 program after the endpoints were manually chosen, so that accurate baselines parallel to the glass and liquid heat capacity curves were drawn. The DSC-2 cal culates the onset value by drawing a tangent at the point of inflection of the heat capacity curve and extending this tangent line to intersect the extended glassy baseline. The intersection point is taken as the onset value of $\mathrm{T}_{\mathrm{g}} \cdot{ }^{50}$

\section{Results}

A. $\mathbf{T}_{\mathbf{g}}$ as a Function of Pore Fullness, Surface Treatment, and Pore Size. The measured values of $\mathrm{T}_{\mathrm{g}}$ and $\Delta \mathrm{C}_{\mathrm{p}}$ at various degrees of pore fullness were examined for o-terphenyl in the 8.5 and $73 \mathrm{~nm} \mathrm{CPG,}$ since these two sizes were assumed to reasonably represent the outermost range of pore sizes available. Only the surface treated CPGs were used for these studies. Typical normalized DSC scans for o-terphenyl

(49) Wunderlich, B.; Bodily, D. M.; Kaplan, M. H. J . Appl. Phys. 1964, 35, 95.

(50) Wunderlich, B.; Cheng, S. Z. D.; Loufakis, K. Encycl. Polym. Sci. Eng.; Wiley: New York, 1989; Vol. 16, p 767. 


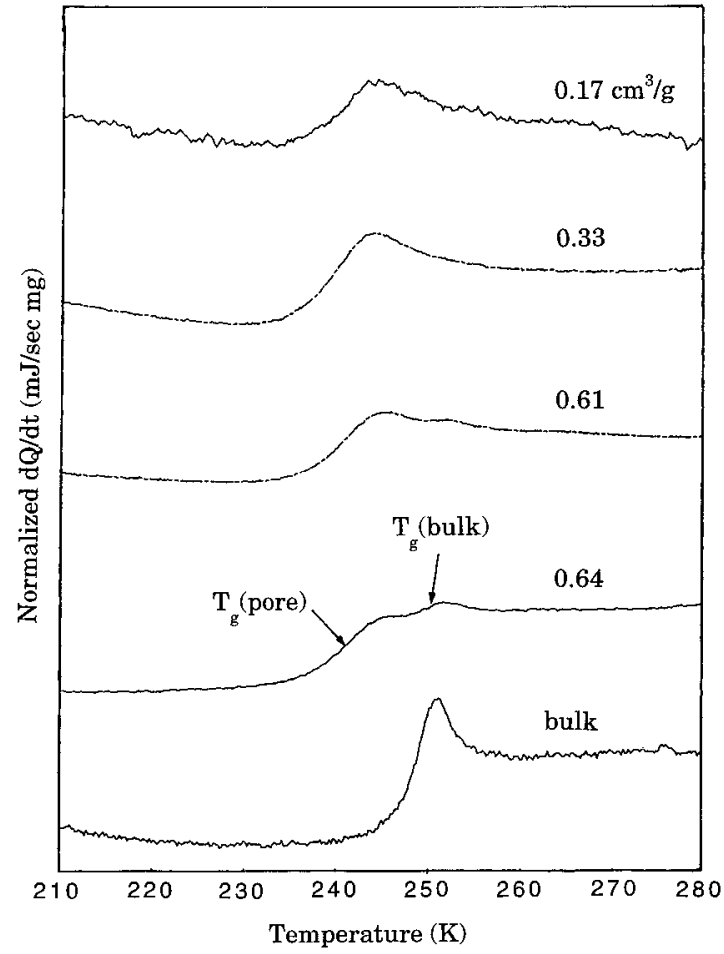

Figure 2. Glass transition temperature shown by the normalized DSC heating curves of o-terphenyl in $8.5 \mathrm{~nm}$ pores of CPG at various degrees of pore filling. No change in $T_{g}$ is observed between pore fillings of 0.16 (27\% full), 0.33 (54\%), $0.61(103 \%)$, and $0.64(108 \%) \mathrm{cm}^{3} / \mathrm{g}$. The $\mathrm{T}_{\mathrm{g}}$ of the pore liquid is $\sim 240 \mathrm{~K}$ (midpoint). The $\mathrm{T}_{\mathrm{g}}$ measured for bulk o-terphenyl is $\sim 248 \mathrm{~K}$, shown at the bottom for reference.

in the $8.5 \mathrm{~nm}$ pores at pore fillings (\% pore fullness) of $0.17(27 \%), 0.33$ (56\%), 0.61 (103\%), and 0.64 (108\%) $\mathrm{cm}^{3} / \mathrm{g}$ are shown in Figure 2, with the behavior of bulk o-terphenyl shown at the bottom for reference. The expected pore volume for the $8.5 \mathrm{~nm}$ diameter CPG is $0.59 \mathrm{~cm}^{3} / \mathrm{g}$ (Table 1). The $T_{g}$ at $d=8.5 \mathrm{~nm}$ is found to be independent of degree of pore filling in the range 27$108 \%$ fullness. The change in $\Delta C_{p}$ at $T_{g}$ is also independent of degree of pore filling, within experimental uncertainty, indicating that the liquid forms plugs, as shown in Figure $1 a$, rather than wetting all the interior surfaces of the glass (Figure 1b). The formation of a plug minimizes the contact of the liquid with the glass surface, suggesting poor wetting characteristics, a high contact angle of the liquid with the interior pore surface and relatively flat menisci for the liquid-vapor interfaces. This result is similar to that observed previously on nonpolar organic liquids which crystallize instead of vitrify. ${ }^{13}$ In Figure 2 at $0.61 \mathrm{~cm}^{3} / \mathrm{g}$ (103\% full) and 0.64 $\mathrm{cm}^{3} / \mathrm{g}$ (108\% full), the pores are slightly overfilled and the $T_{g}$ of the bulk liquid becomes apparent as well. The measured values of $T_{g}$ for the data in Figure 2 and for o-terphenyl in a larger pore diameter $(\mathrm{d}=73 \mathrm{~nm}) \mathrm{CPG}$ are given in Table 2 . No dependence of $T_{g}$ or $\Delta C_{p}$ on pore fullness was measured at either pore size.

A limited study of the effect of surface treatment of the CPG on the measured values of $T_{g}$ for both oterphenyl and benzyl alcohol was done using the $8.5 \mathrm{~nm}$ CPG material. Surface treatment of the CPG with hexamethyldisilazane (HMDS) converts the polar surface hydroxyl groups to nonpolar trimethyl silyl groups. We observed that HMDS treatment had a small effect on the shift in $T_{g}$ for both o-terphenyl and benzyl alcohol, with $\Delta \mathrm{T}_{\mathrm{g}}$ in the treated CPG larger by $1-2 \mathrm{~K}$
(Tables 2 and 3). If the values for the treated and untreated CPG are subjected to a statistical t-test, they are found to be significantly different at a $95 \%$ confidence level. ${ }^{51}$ The observed increase in $\Delta \mathrm{T}_{\mathrm{g}}$ may reflect a small reduction in pore size for the treated CPG, as has been measured for silica gels treated with similar derivatives. ${ }^{52}$ The wetting characteristics of the organic liquid are also changed by the surface treatment, but this effect is difficult to measure. The fact that the change in $\Delta \mathrm{T}_{\mathrm{g}}$ with surface treatment can be accounted for by the small change in pore size implies that surface interactions between the glass and the organic liquid are not very significant. This supports the hypothesis of plug formation at low pore fillings and minimal surface interaction, given previously. It is also in agreement with the work of Liu et al., 53 who studied the spin-lattice relaxation times of strongly interacting (polar) and weakly interacting (nonpolar) liquids in similar types of porous glass by nuclear magnetic resonance (NMR). They reported that weakly interacting liquids, such as cyclohexane and cis-decalin, have very little surface interaction with either treated or untreated glass surfaces.

The effect of pore size on the value of $T_{g}$ for both o-terphenyl and benzyl alcohol was measured for the entire range of pore sizes $(4-73 \mathrm{~nm})$ and is shown in Figure 3. The value of the glass transition temperature at a given pore diameter, $T_{g}(d)$, is reduced relative to the bulk $T_{g}$ as a function of inverse pore diameter. For example, o-terphenyl has a $\mathrm{T}_{\mathrm{g}}$ value of $239.4 \pm 0.6 \mathrm{~K}$ in the $8.5 \mathrm{~nm}$ pores, in the pore fullness range $0.16-0.79$ $\mathrm{cm}^{3} / \mathrm{g}$ in the treated CPG materials (Table 2). The $T_{\mathrm{g}}$ values plotted in Figure 3 were measured as the midpoint of the transition region of the curve. In comparison, the $T_{g}$ of bulk o-terphenyl was measured to be $248.1 \pm 0.5 \mathrm{~K}$. For benzyl alcohol, the $T_{g}(d)$ was measured to be $164.9 \pm 0.5 \mathrm{~K}$ in the $8.5 \mathrm{~nm}$ pores, in the pore fullness range $0.42-0.69 \mathrm{~cm}^{3} / \mathrm{g}$ for benzyl alcohol in the treated CPG materials. The $T_{g}$ of bulk benzyl alcohol was measured to be $168.7 \mathrm{~K}$, for comparison.

The onset values for $T_{g}$ are al so given in Tables 2 and 3 , so that an estimate of the breadth of the transition region can be made. The o-terphenyl confined in the $8.5 \mathrm{~nm}$ diameter CPG material has a broader transition range than the bulk o-terphenyl, with $\mathrm{T}_{g}$ (midpoint) $\mathrm{T}_{\mathrm{g}}$ (onset) equal to $2.6{ }^{\circ} \mathrm{C}$ versus $0.8{ }^{\circ} \mathrm{C}$ for the bulk material. In all cases, however, the magnitude of the enthal py recovery peak in the bulk liquid is larger than that measured for the pore liquid and this makes accurate measurement of the breadth of the transition range difficult. For benzyl alcohol in the $8.5 \mathrm{~nm}$ pores, $\mathrm{T}_{\mathrm{g}}$ (midpoint) $-\mathrm{T}_{\mathrm{g}}$ (onset) is equal to $1.1^{\circ} \mathrm{C}$ versus 1.2 ${ }^{\circ} \mathrm{C}$ for the bulk material, so the transition breadth is approximately the same in this case. The $\Delta C_{p}$ at $T_{g}$ was also measured and found to be comparable for the confined and bulk materials, within experimental error (Tables 2 and 3).

B. Crystallization in a Confined Geometry. For o-terphenyl, crystallization of the pore liquid was not

(51) Peters, D. G.; Hayes, J . M.; Hieftje, G. M. Chemical Separations and Measurements; W. B. Saunders: Philadel phia, 1974; p 27.

(52) Sands, D. W.; Kim, Y. S.; Bass, J . L. J . Chromatogr. 1986, 360, 353.

(53) Liu, G.; Li, Y.; J onas, J . J . Chem. Phys. 1991, 95, 6892. 
Table 2. Effect of Pore Filling and Surface Treatment on $T_{g}$ and $\Delta C_{p}$ of o-Terphenyl

\begin{tabular}{|c|c|c|c|c|c|c|}
\hline pore size & CPG surface & total $\left(\mathrm{cm}^{3} / \mathrm{g}\right)$ & $\%$ full & midpoint $T_{g}(K)$ & onset $T_{g}(K)$ & $\Delta C_{p}(\mathrm{~J} / \mathrm{g}$ deg $)$ \\
\hline \multirow[t]{2}{*}{$8.5 \mathrm{~nm}$} & HMDS treated & $\begin{array}{l}0.17 \\
0.33 \\
0.61 \\
0.64^{a} \\
0.79^{a}\end{array}$ & $\begin{array}{l}27 \\
56 \\
103 \\
108 \\
134\end{array}$ & $\begin{array}{c}239.4 \\
238.8 \\
239.8 \\
238.9 \\
240.3 \\
\text { avg }^{b} 239.4 \pm 0.6\end{array}$ & $\begin{array}{l}237.7 \\
236.6 \\
236.7 \\
235.8 \\
237.8 \\
236.8 \pm 0.7\end{array}$ & $\begin{array}{l}0.63 \\
0.50 \\
0.46 \\
0.42 \\
0.40 \\
0.48 \pm 0.09\end{array}$ \\
\hline & untreated & $\begin{array}{l}0.56 \\
0.70 \\
0.72\end{array}$ & $\begin{array}{l}95 \\
119 \\
122\end{array}$ & $\begin{array}{c}242.0 \\
240.6 \\
241.1 \\
\text { avg }^{b} 241.2 \pm 0.7\end{array}$ & $\begin{array}{l}239.5 \\
238.0 \\
238.2 \\
238.6 \pm 0.8\end{array}$ & $\begin{array}{l}0.42 \\
0.44 \\
0.42 \\
0.43 \pm 0.01\end{array}$ \\
\hline 73.0 & HMDS treated & $\begin{array}{l}0.46 \\
0.77 \\
1.03 \\
\\
N A^{c}\end{array}$ & $\begin{array}{l}47 \\
77 \\
105 \\
\text { NA }\end{array}$ & $\begin{array}{c}244.2 \\
243.0 \\
243.9 \\
\text { avg }^{\mathrm{b}} 243.7 \pm 0.6 \\
\text { avgb }^{\mathrm{b}} 248.1 \pm 0.5\end{array}$ & $\begin{array}{l}241.0 \\
239.8 \\
241.7 \\
240.8 \pm 1.0 \\
247.3 \pm 0.8\end{array}$ & $\begin{array}{l}0.53 \\
0.54 \\
0.46 \\
0.51 \pm 0.06 \\
0.54 \pm 0.08\end{array}$ \\
\hline
\end{tabular}

a Observe some exotherm on heating for excess bulk liquid. ${ }^{b}$ Mean of data \pm 1 standard deviation. ${ }^{\mathrm{C}}$ NA $=$ not applicable.

Table 3. Effect of Pore Filling and Surface Treatment on $T_{g}$ and $\Delta C_{p}$ of Benzyl Alcohol

\begin{tabular}{|c|c|c|c|c|c|c|}
\hline pore size & CPG surface & total $\left(\mathrm{cm}^{3} / \mathrm{g}\right)$ & $\%$ full & midpoint $T_{g}(K)$ & onset $\mathrm{T}_{\mathrm{g}}(\mathrm{K})$ & $\Delta \mathrm{C}_{\mathrm{p}}(\mathrm{J} / \mathrm{g}$ deg $)$ \\
\hline $8.5 \mathrm{~nm}$ & HMDS treated & $\begin{array}{l}0.42 \\
0.51 \\
0.55 \\
0.64 \\
0.69 \\
0.76\end{array}$ & $\begin{array}{r}72 \\
86 \\
93 \\
108 \\
117 \\
129\end{array}$ & $\begin{array}{c}164.2 \\
164.8 \\
165.1 \\
165.4 \\
165.6 \\
\mathrm{NO}^{\mathrm{c}} \\
\text { avg }^{\mathrm{b}} 165.0 \pm 0.5\end{array}$ & $\begin{array}{l}163.1 \\
163.6 \\
164.1 \\
164.0 \\
164.6 \\
N^{C} \\
163.9 \pm 0.6\end{array}$ & $\begin{array}{c}0.50 \\
0.42 \\
0.46 \\
0.46 \\
0.38 \\
\mathrm{NO}^{\mathrm{C}} \\
0.46 \pm 0.04\end{array}$ \\
\hline butl & untreated & $\begin{array}{l}0.61 \\
0.74 \\
0.85^{a}\end{array}$ & $\begin{array}{l}103 \\
125 \\
144\end{array}$ & $\begin{array}{c}166.3 \\
166.4 \\
\mathrm{NO}^{c} \\
\text { avg }^{\mathrm{b}} 166.2 \pm 0.3\end{array}$ & $\begin{array}{l}164.8 \\
165.0 \\
\mathrm{NO}^{\mathrm{c}} \\
164.9 \pm 0.14\end{array}$ & $\begin{array}{l}0.38 \\
0.38 \\
N^{c}\end{array}$ \\
\hline
\end{tabular}

a Observe some exotherm on heating for pore liquid. ${ }^{b}$ Mean of data \pm 1 standard deviation. ${ }^{c} \mathrm{NO}=$ not observed since benzyl alcohol crystallized in pores. $\mathrm{d}$ NA $=$ not applicable.

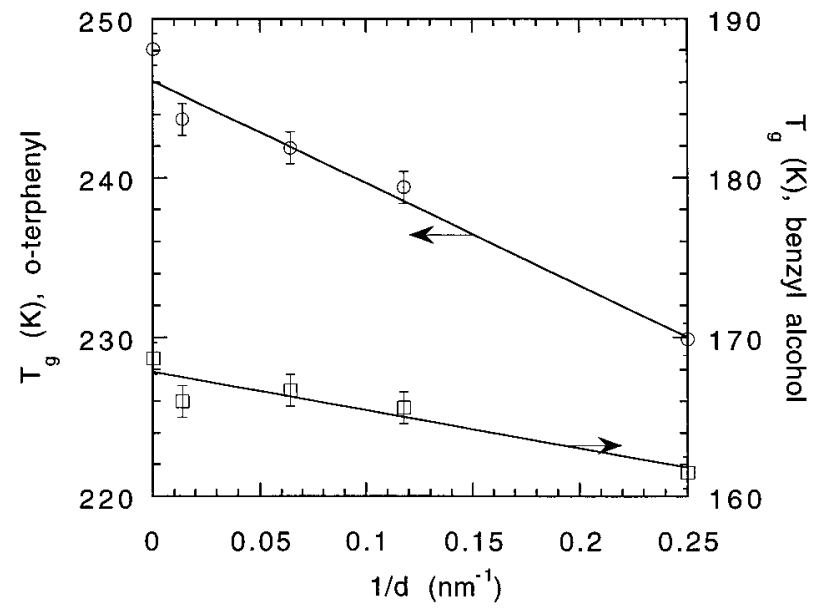

Figure 3. $T_{g}$ versus $1 / d$ for o-terphenyl (circles) and benzyl alcohol (squares).

observed under most of the experimental conditions studied, regardless of whether the pores were underfilled or overfilled. A full heating scan for one of the underfilled materials $\left(0.56 \mathrm{~cm}^{3} / \mathrm{g}\right.$ in untreated CPG) in the $8.5 \mathrm{~nm} \mathrm{CPG}$ is shown in Figure 4, where neither crystallization nor melting of the pore liquid is observed after the glass transition event. When the pores are slightly overfilled with o-terphenyl, a bulk melting peak is observed at $329 \mathrm{~K}$. This is shown in Figure 4 for a concentration of $0.64 \mathrm{~cm}^{3} / \mathrm{g}$. The melting endotherm represents the amount of o-terphenyl outside the pores, as calculated from the measurement of $\Delta \mathrm{H}_{\mathrm{f}}$ and the value of the bulk $\Delta \mathrm{H}_{\mathrm{f}}$ reported for o-terphenyl. A small exotherm is also observed on heating, indicating that the excess o-terphenyl was glassy at the start of the heating run and further evidenced by the very weak $T_{g}$ indicated at $248 \mathrm{~K}$ in Figure 4. This dual behavior is not surprising, as the method used to prepare the glass (cooling the melt at $10 \mathrm{~K} / \mathrm{min}$ ) is easily applied to bulk material, as well. For example, a DSC scan of pure bulk o-terphenyl is shown for reference at the bottom of Figure 4; an exotherm on heating is also seen in this case. o-Terphenyl is known to crystallize more sluggishly than other organic compounds, the crystallization process is reported to take about 4 days to reach completion when it is conducted around the glass transition range, but at higher temperatures the crystallization process is mostly completed within $1 / 2 \mathrm{~h} .{ }^{47}$ It is surprising, however, that the pore liquid in pores as large as $15.6 \mathrm{~nm}$, for example, did not crystallize after annealing 2 months at room temperature followed by holding at $260 \mathrm{~K}$ for $2 \mathrm{~h}$, prior to the heating cycle. Only in the largest diameter CPG $(73 \mathrm{~nm})$, where bulk behavior is approximated most closely, was the pore liquid ever observed to crystallize for o-terphenyl.

In contrast, the crystallization behavior of benzyl alcohol depends systematically on the pore size. In the $4.0 \mathrm{~nm} \mathrm{CPG}$, crystallization of the pore liquid was never observed even if excess pore material was present as crystals. In the $8.5 \mathrm{~nm} \mathrm{CPG}$, crystallization occurs readily when the pores are overfilled and the sol idification behavior of the pore liquid is greatly influenced by the excess pore liquid, as shown in Figure 5 . When the pores are underfilled, the pore liquid does not crystallize after the glass transition occurs on heating but is stable 


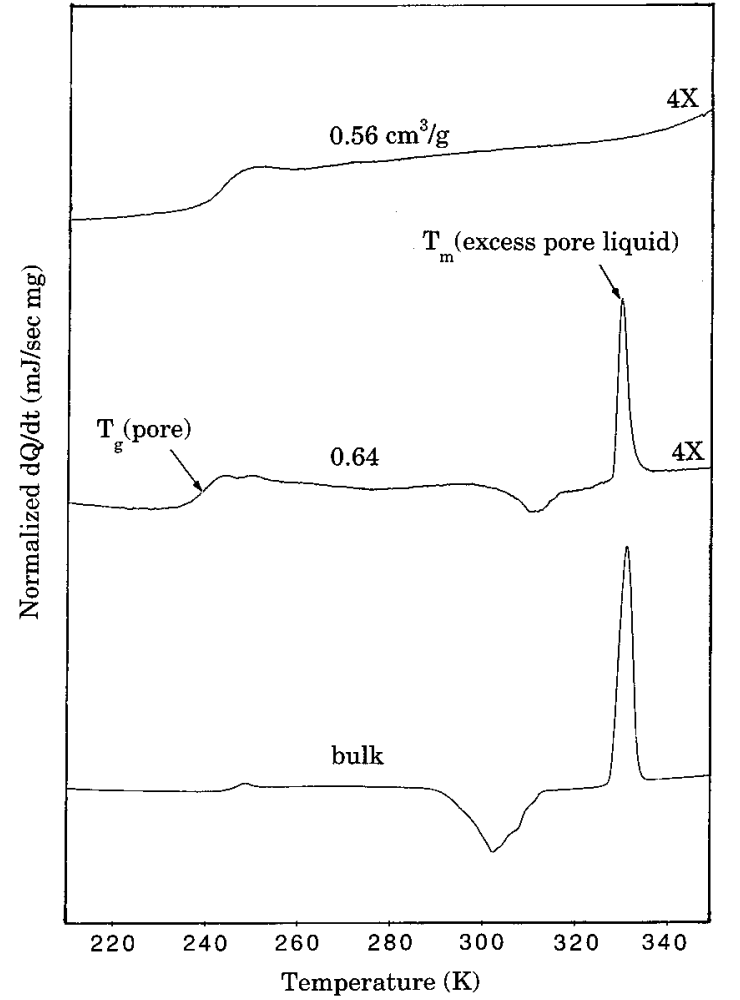

Figure 4. Effect of pore fullness on glass formation versus crystallization for o-terphenyl in the $8.5 \mathrm{~nm}$ pores of CPG. At $0.56 \mathrm{~cm}^{3} / \mathrm{g}$ (95\% full) in the untreated CPG, the pores are almost filled and crystallization of the pore liquid is not observed. At $0.64 \mathrm{~cm}^{3} / \mathrm{g}$ (108\%) in the treated CPG, the pores are overfilled, the excess pore material shows an exotherm and a melting endotherm at $329 \mathrm{~K}$, but the pore liquid does not crystallize. The thermal behavior of pure o-terphenyl is shown for reference at the bottom. See text for details.

in the pores as an undercooled liquid $\left(0.42\right.$ and $0.64 \mathrm{~cm}^{3} /$ g). When the pores are slightly overfilled with benzyl alcohol, a glass forms both in the pores and in the excess pore material, as shown for the $0.85 \mathrm{~cm}^{3} / \mathrm{g}$ concentration. When this occurs, a crystallization exotherm (at $205 \mathrm{~K}$ ) is always observed on heating, after the glass transition event. Alternatively, crystallization may occur during the cooling cycle, as shown for the 0.95 $\mathrm{cm}^{3} / \mathrm{g}$ concentration in Figure 5 and evidenced by the lack of $\mathrm{T}_{\mathrm{g}}$ and the absence of a crystall ization exotherm on heating. In either case, the melting point of the crystalline material in the pores occurs at $\sim 230 \mathrm{~K}$ and follows the behavior expected from the Gibbs-Thomson equation (eq 1). The bulk melting temperature of the excess pore material is seen at the normal melting point of $257.8 \mathrm{~K}$. (The small endotherm at $242 \mathrm{~K}$ is due to an impurity in the benzyl alcohol, which also appears as a shoulder on the melting endotherm of the bulk "pure" benzyl alcohol.) The behavior of benzyl alcohol in pores larger than $8.5 \mathrm{~nm}$ is less complex, as crystallization of the pore liquid above $T_{g}$ proceeds readily regardless of whether the pores are underfilled or overfilled. Thus, pore size plays a critical role in the solidification behavior of both benzyl alcohol and oterphenyl.

\section{Discussion}

A. Effect of Finite Size on the $T_{g}$ of Organic Glasses. The effect of finite size on $T_{g}$ cannot be interpreted as readily as the decrease in the melting

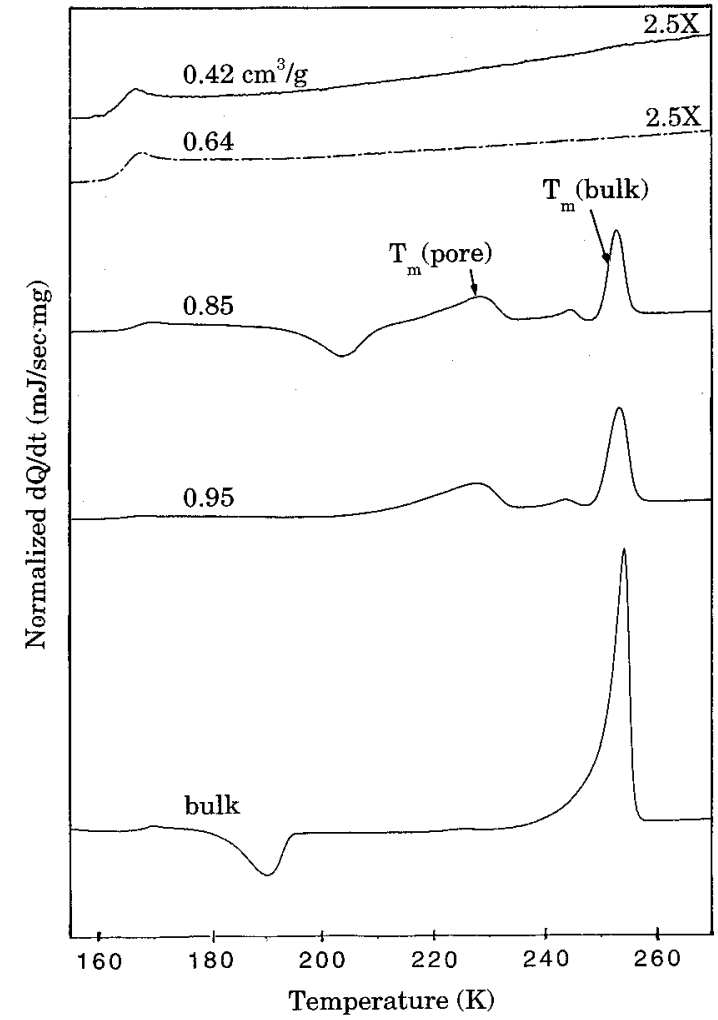

Figure 5. Effect of porefullness on the glass formation versus crystallization shown by normalized DSC heating scans of benzyl alcohol in the $8.5 \mathrm{~nm}$ pores of CPG. At 0.42 (72\% full) and $0.64(108 \%) \mathrm{cm}^{3} / \mathrm{g}$, the pores are underfilled and no crystallization of the pore liquid is observed. At $0.85 \mathrm{~cm}^{3} / \mathrm{g}$ (144\% full) and $0.95 \mathrm{~cm}^{3} / \mathrm{g}(161 \%)$, the pores are overfilled and the pore liquid easily forms crystals. A broad melting endotherm is observed for the pore liquid at $228 \mathrm{~K}$ and a bulk melting endotherm is observed for the excess pore liquid at $254 \mathrm{~K}$. The quenched glass of pure benzyl alcohol (in the presence of a nonporous glass powder) is shown at the bottom for comparison. See text for details.

transition, $T_{m}$, which is well described by the GibbsThomson equation (eq 1). This difficulty is in part due to the lack of a consensus on the nature of the glass transition. ${ }^{54,55}$ Under these circumstances it is reasonable, however, to compare this transition phenomenon with equilibrium phase transitions which are better understood. For example, the glass transition is often compared to second order transitions such as are predicted by the Ising model, which describes a variety of fluid phase separation and magnetic ordering transitions. The critical temperature of the two-dimensional I sing model is lower than that of the three-dimensional I sing model, ${ }^{56}$ so that confinement might be expected to shift the transition temperature downward. Theoretical predictions indicate a shift of this kind, ${ }^{57} \Delta T_{c} \sim$ $1 / \mathrm{d}^{\delta}$, where $\delta$ is a noninteger critical exponent related to the particular type (universality class) of second-order transition involved. In a mean-field approximation, this exponent equals 2 for the Ising model and other similar second order phase transitions. On the basis of the analogy with second-order phase transitions, Keddie et al. ${ }^{24}$ have studied the shift in $T_{g}$ for thin films of

(54) McKenna, G. B. In Comprehensive Polymer Science; Booth, C., Price, C., Eds.; Pergammon Press: Oxford, 1989; Vol. 2, p 311.

(55) Proceedings of a Workshop on "Glasses and the Glass Transition"; Comput. Mater. Sci. 1995, 4, 283-385.

(56) Douglas, J . F.; Ishinabe, T. Phys. Rev. E 1995, 51, 1791.

(57) Nakanishi, H.; Fisher, M. E. J . Chem. Phys. 1983, 78, 3279. 


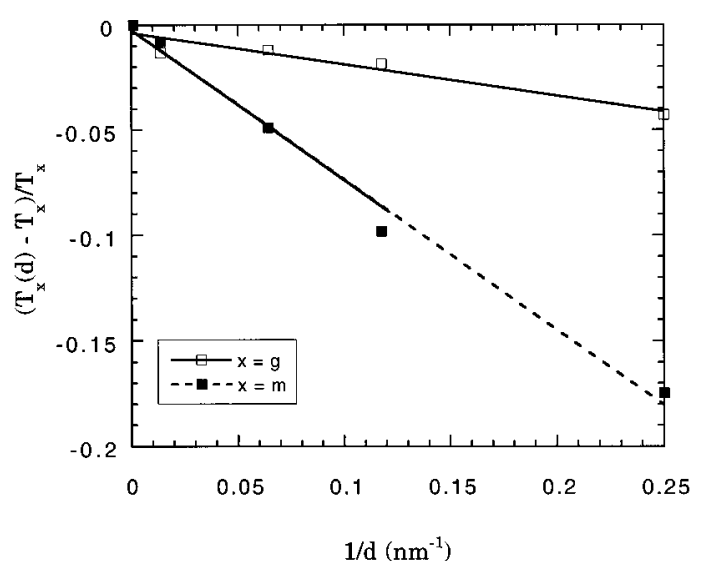

Figure 6. $\left(T_{g}(d)-T_{g}\right) / T_{g}$ and $\left(T_{m}(d)-T_{m}\right) / T_{m}$ versus $1 / d$ for benzyl alcohol. The data for $T_{m}\left(1 / d=0.25 \mathrm{~nm}^{-1}\right)$ was calculated using eq 1 , since crystallization of the pore liquid was not observed in the $4.0 \mathrm{~nm}$ pores, and the extended curve is shown as a dashed line.

polystyrene and examined plots of the form, $\Delta T_{g} \sim 1 / d^{\delta}$. They estimate that in this system, $\delta=1.8$. Sappelt and $\mathrm{J}$ äckle ${ }^{58}$ have developed a model of the effect of finite size on $T_{g}$, which borrows ideas from the theory of second-order phase transitions and predicts a downward shift and a broadening of $T_{g}$ from finite size constraints on the "correlation length" defined for the glass. Lobe and Baschnagel ${ }^{18}$ have studied finite size effects on simulated polymer glasses and have predicted a downward shift in $\mathrm{T}_{\mathrm{g}}$ as well.

Our experimental results show that $T_{g}$ shifts to lower temperature as the pore size decreases for both benzyl alcohol and o-terphenyl (Figure 3). Thus, the experimental results presented here and those published previously ${ }^{16}$ are qualitatively consistent with the second order transition analogy. ${ }^{18,58,59}$ In addition, some evidence for broadening of $\mathrm{T}_{\mathrm{g}}$ is measured in the confined glass for o-terphenyl, as shown by the difference in the onset and midpoint values of the $\mathrm{T}_{\mathrm{g}}$ given for the data in the 8.5 and $73 \mathrm{~nm}$ pores in Table 2, compared to the data for the bulk material. Broadening of the glass transition region was not observed in the case of benzyl alcohol in the $8.5 \mathrm{~nm} \mathrm{CPG} \mathrm{(Table} \mathrm{3),} \mathrm{and} \mathrm{no} \mathrm{explanation}$ for the difference in broadening behavior for o-terphenyl and benzyl alcohol is known at this time.

A comparison between the observed shift in $\mathrm{T}_{\mathrm{g}}$ due to finite-size effects and the shift expected for first order phase transitions, such as melting, due to finite-size effects is also instructive. Kauzmann ${ }^{1}$ long ago noted that the ratio of $T_{g}$ and $T_{m}$ was often near $2 / 3$ for many glass forming liquids, with later refinements made by others to account for different classes of glass-forming liquids. ${ }^{60}$ This observation suggests that the glass and melting transitions reflect a common tendency toward order, even if the transitions do not belong to the same class, and that the transition temperatures might vary similarly. This heuristic reasoning motivated the initial comparison of $T_{g}$ and $T_{m}$ in finite-size measurements in our first paper. ${ }^{16}$ A direct comparison of the reduced shift in the glass transition temperature, $\Delta \mathrm{T}_{\mathrm{g}} / \mathrm{T}_{\mathrm{g}}$ and the reduced shift in melting temperature, $\Delta T_{m} / T_{m}$, versus $1 / d$ is made for benzyl alcohol in Figure 6.

(58) Sappelt, D.; J ackle, J . J . Phys. A 1993, 26, 7325.

(59) Hunt, A. Solid State Commun. 1994, 90, 527.

(60) Fedors, R. F. J . Polym. Sci.: Polym. Lett. Ed. 1979, 17, 719.
Although the shift in $\mathrm{T}_{\mathrm{g}}$ is in the same direction as the shift in $T_{m}$, the slopes of the two lines are so different that it suggests the empirical relationship observed by Kauzmann does not apply to changes imposed by finitesize effects.

The two classical approaches to the glass transition event, the configurational entropy model of Gibbs and DiMarzio61,62 and the general class of free-volume model $s^{63,64}$ might cause one to look for al ternate explanations for the observed decrease in $\mathrm{T}_{\mathrm{g}}$ in a hydrostatic tension in the confined liquid. If only entropy theory is considered, the decrease in entropy due to the confinement is expected to result in an increase in $\mathrm{T}_{\mathrm{g}}$. On the other hand, both the entropy theory and the free volume models suggest that a decrease in density, due to a hydrostatic tension, could cause the observed decrease in $\mathrm{T}_{\mathrm{g}}$ as pore size decreases. For example, a reduction in bulk density might occur if a negative pressure is generated by "stretching" the liquid 65 across a concave meniscus in the pores, as the temperature is reduced. Zhang et al ${ }^{66}$ have suggested that a negative pressure could be responsible for the observed downward shift in $\mathrm{T}_{\mathrm{g}}$ in a confined geometry. We believe the data showing that $T_{g}$ is not a function of pore fullness for o-terphenyl (Figure 3) make it unlikely that a negative pressure induced by surface tension is responsible for the shift in $T_{g}$. The data suggest that the pore filling mechanism is as shown in Figure la. The radius of curvature of the menisci for the liquid "plugs" must be concave for capillary condensation to occur, but since the organic does not wet the glass surface well, the contact angle must be greater than zero. This implies that the liquid menisci are relatively flat. As the glass forms upon cooling the liquid, however, the shape of the solid menisci is unknown and may be either concave or convex. ${ }^{11}$

Another mechanism that might induce a negative pressure arises from the mismatch in coefficient of thermal expansion between the organic liquid and the $\mathrm{SiO}_{2}$ matrix. A calculation of the magnitude of the negative pressure was made ${ }^{67}$ and found to be insufficient to explain the observed shifts in $\mathrm{T}_{\mathrm{g}}$. The volumetric coefficient of thermal expansion, $\alpha$, of glassy o-terphenyl is $\sim 2 \times 10^{-4} / \mathrm{K}, 68$ which is much larger than $\alpha$ for porous $\mathrm{SiO}_{2}$ glass $\left(5.5 \times 10^{-7} / \mathrm{K}^{69}\right)$. As the liquid is cooled inside the pores, a negative pressure $P$, may be generated due to a contraction of the liquid, assuming the liquid adheres to the pore surface. The negative pressure which would be generated is related to the bulk modulus of the organic glass, $\mathrm{K}$, the change in volume, $\Delta \mathrm{V}$, and the specific vol ume of the liquid, $\mathrm{V}_{0}$, according to the relationship

$$
\mathrm{P}=\mathrm{K}\left(\left(\Delta \mathrm{V} / \mathrm{N}_{0}\right)-1\right)
$$

(61) Gibbs, J . H.; DiMarzio, E. A. J . Chem. Phys. 1958, 28, 323.

(62) DiMarzio, E. A.; Gibbs, J . H. J . Chem. Phys. 1958, 28, 807.

(63) Robertson, R. E.; Simha, R.; Curro, J . G. Macromol ecules 1985, 18,2239 .

(64) Curro, J. G.; LaGasse, R. R.; Simha, R. Macromolecules 1982, 15, 1621.

(65) Angell, C. A.; Quing, Z. Phys. Rev. B 1989, 39, 8784.

(66) Zhang, J .; Liu, G.; J onas, J. J . Phys. Chem. 1992, 96, 3478.

(67) Timoshenko, S. P.; Goodier, J . N. Theory of Elasticity, 3rd ed.; McGraw-Hill: New York, 1970.

(68) Cukierman, M.; Lane, J. W.; Uhlmann, D. R. J . Chem. Phys. 1973, 59, 3639.

(69) Handbook of Chemistry and Physics, 56th ed.; Weast, R. C. Ed: Chemical Rubber Co.: Cleveland, 1975. 
Since $\left(\Delta \mathrm{V} N_{0}\right)-1=\alpha \Delta \mathrm{T}$, the calculated value of $\mathrm{P}$ resulting from a temperature increment of $\Delta T=10 \mathrm{~K}$ is $4 \mathrm{MPa}$, assuming the bulk modulus of the organic glass is $2 \mathrm{GPa}^{70} \mathrm{~F}$ or a change of $4 \mathrm{MPa}$ in pressure, the estimated shift in $T_{g}$ for o-terphenyl is only $1 \mathrm{~K}$, since the pressure dependence of $T_{g}$ has been measured to be $26 \mathrm{~K} / 100 \mathrm{MPa}$ (1 kbar). ${ }^{71}$ Thus, the calculated shift in $\mathrm{T}_{\mathrm{g}}$ due to negative pressure is much too small to explain the experimental data for o-terphenyl. Additionally, if a negative pressure is assumed to cause the observed effect, it remains to be explained why the magnitude of the negative pressure is estimated to be similar for both o-terphenyl and benzyl alcohol, yet the shifts in $T_{g}$ are observed to be very different ( $F$ igure 2 ), as well as why $T_{g}$ depends on pore size, which does not appear in eq 2.

Although precautions were taken in this work to prepare and maintain clean, untreated CPGs and surface treated CPGs, we have considered the possibility that the downward shift in $\mathrm{T}_{\mathrm{g}}$ as a function of $1 / \mathrm{d}$ might be caused by water or other impurities adsorbed on the interior CPG surfaces. If adsorbed impurities became dissolved in the organic liquid, a plasticization or diluent effect would shift the $T_{g}$ downward. ${ }^{72}$ We offer some observations on the data we have gathered that contradict this hypothesis. First, most surface adsorbed organic impurities would be expected to dissolve similarly in both benzyl alcohol and o-terphenyl, while surface adsorbed water would be expected to dissolve more easily in benzyl alcohol. Since the reduction in $\mathrm{T}_{\mathrm{g}}$ is proportional to the moles of impurity per mole of "monomer", the shift is largest for low molecular weight impurtities such as water. ${ }^{72}$ The shift in $\mathrm{T}_{\mathrm{g}}$ for the two compounds studied is very different, as shown in Figure 3 , and o-terphenyl shows a much larger shift at any given pore diameter. This observation is not consistent with the expected solubility of the adsorbed impurities. Second, the untreated CPG adsorbs more impurities than the treated CPG and was observed to turn slightly yellow after several months. ${ }^{73}$ If there are more impurities present on the untreated CPG surfaces, the shift should be larger in this case. This is opposite of the behavior reported in $8.5 \mathrm{~nm} \mathrm{CPG}$ for both o-terphenyl and benzyl alcohol, where the treated CPG had a 1-2 $\mathrm{K}$ larger shift in $\mathrm{T}_{\mathrm{g}}$. This additional shift was interpreted as a slight reduction in pore size due to the surface treatment, as discussed above. Also, prelimi-

(70) We could not find a literature value for the bulk modulus of o-terphenyl glass, so a value was estimated from the compressibility, $\kappa$, of various organic liquids. For example, benzene at $0^{\circ} \mathrm{C}$ has $\kappa=8$ $\times 10^{-4} / \mathrm{MPa}$, and this value does not vary substantially for other organic liquids. Since the bulk modulus is related to the compressibility as $\mathrm{K}=1 / \kappa$, the bulk modulus is estimated to be $1.25 \mathrm{GPa}$. We use a value of $2 \mathrm{GPa}$ since the glass is expected to have a slightly lower compressibility than the liquid and thus a higher modulus.

(71) Atake, T.; Angell, C. A. J . Phys. Chem. 1979, 83, 3218.

(72) DiMarzio, E. A.; Castellano, C.; Yang, A. J . Polym. Sci.: Part B: Polym. Phys. 1996, 34, 535.

(73) Thermogravimetric analysis (TGA) in air of the $8.5 \mathrm{~nm}$ diameter CPGs showed about $1.0 \%$ weight loss up to $105{ }^{\circ} \mathrm{C}$ for the treated CPG and $2.5 \%$ weight loss up to $105^{\circ} \mathrm{C}$ for the untreated CPG. Assuming that this weight loss is adsorbed water, the amount of impurity present is over twice as great for the untreated CPG. From 105 to $300{ }^{\circ} \mathrm{C}$, both the treated and untreated CPG showed an additional weight loss of $1 \%$. Each sample was run in triplicate and showed excellent reproducibility. The desorption of the adsorbed water and other impurities on the surface at el evated temperatures does not guarantee desorption and dissolution into the imbibed liquid at the much lower temperatures employed in this work, but unless strict vacuum procedures are used it is an unavoidable issue in working with porous glasses such as CPGs or Vycor glass. nary enthalpy recovery experiments by DSC showed that the decrease in $T_{g}$ was accompanied by the observation of longer structural recovery times for the glass, which is not consistent with a plasticization effect. ${ }^{74}$ Finally, in our parallel study on the melting of small crystals confined in the same series of CPG materials, ${ }^{13}$ the results followed eq 1 and no anomal ous additional reduction in melting point was observed which would be caused by the presence of impurities. These observations are indirect but suggest that the downward shift in $T_{g}$ is not a result of plasticiation by impurities adsorbed on the glass surface.

Other studies of $T_{g}$ of mostly hydrogen-bonding type organic glasses in porous materials have recently been made using both DSC and other types of measurement techniques. The results are conflicting and may reflect the difficulty in comparing measurements of $T_{g}$ made by various techniques, 55 as well as differences in the host materials employed. Zhang et al. ${ }^{66}$ observed that $\mathrm{T}_{\mathrm{g}}$ was inversely related to pore diameter for the glass forming liquids, isopropylbenzene, glycerol, di-n-butyl phthalate, tert-butylbenzene, and n-butyl acetate in porous silica using DSC measurements. Their experimental results agree with our findings, but the interpretation they provide is that of a negative pressure effect. For propylene glycol (PG) in porous Vycor glass (pore diameter $\approx 4 \mathrm{~nm}$ ), Pissis et al..$^{75}$ report that the $\mathrm{T}_{\mathrm{g}}$ decreases by $\sim 10 \mathrm{~K}$, using thermally stimulated depolarization current (TSDC) measurements. No comparable DSC measurements are available. Schuller et al. ${ }^{76}$ also studied PG and two of its oligomers, poly(propylene glycol) (PPG) of 400 and $725 \mathrm{~g} / \mathrm{mol}$, in CPG with a pore diameter of $10 \mathrm{~nm}$, using dielectric relaxation spectroscopy. They report that $\mathrm{T}_{\mathrm{g}}$ increases slightly (2 K) for PPG, but the pore diameter studied in this case $(10 \mathrm{~nm})$ may be too large to observe a finitesize effect in such a polar liquid. For example, we observed a shift of only $2 \mathrm{~K}$ for benzyl alcohol in untreated CPG of $8.5 \mathrm{~nm}$ pore diameter (Table 3). PPG is an exceptional polymer to choose to study the effect of molecular weight on $T_{g}$, since for polymers with hydroxyl end groups the $T_{g}$ is known to be independent of molecular weight, in contrast to the behavior of most other types of polymers. 55,77

B. Vitrification versus Crystallization of Organic Liquids in Confined Geometries. The fundamental question of whether a liquid will solidify by crystallizing or by undercooling to an amorphous, glassy solid has been considered for many years. In general, since substances are more stable in the crystal line state than in the glassy state, crystallization must be bypassed in order to form a glass. Turnbull and Cohen ${ }^{3}$ sought to explain why glass formation occurs more easily in certain compounds and found an empirical relationship correlating the ease of glass formation to the ratio of the normal boiling point, $\mathrm{T}_{\mathrm{b}}$, with the normal melting point, $T_{m}$. If $T_{b} / T_{m}$ was greater than 2.0, a glass could easily be prepared. ${ }^{3}$ This correlation was later used by Angell and co-workers ${ }^{6}$ and examined with

(74) McKenna, G. B.; J ackson, C. L.; O'Reilly, J . M.; Sedita, J . S. Am. Chem. Soc., Polym. Prepr. (Div. Polym. Sci.) 1992, 33, 118.

(75) Pissis, P.; Daoukaki-Diamanti, D.; Apekis, L.; Christodoulides, C. J. Phys.: Condens. Matter 1994, 6, L325.

(76) Schuller, J.; Yu, B.; Mel'nichenko, B.; Richert, R.; Fischer, E. W. Phys. Rev. Lett. 1994, 73, 2224.

(77) Faucher, J. A. J . Polym. Sci., Polym. Lett. 1965, 3, 143. 
respect to "fragility" of glass-forming liquids, a concept introduced by Angell to classify different liquids. In this description, inorganic liquids are "strong" gl ass formers while most organic liquids are weak or "fragile" glass formers. Angell et al. have argued that low melting points relative to boiling points would result in sluggish crystallization, and attribute this to the poor packing efficiency of certain substances in the crystalline state, where three-dimensional order is a requirement which places constraints on the molecular arrangements. ${ }^{6}$ According to this scheme, o-terphenyl and benzyl al cohol should have similar character since they have nearly the same ratio, $\mathrm{T}_{\mathrm{b}} / \mathrm{T}_{\mathrm{m}} \approx 1.85$.

We observe a marked contrast in the solidification behavior for benzyl alcohol and o-terphenyl, despite the near constancy of $T_{b} / T_{m}$ for the two compounds. Crystallization is never observed for benzyl alcohol inside the $8.5 \mathrm{~nm}$ CPG when the pores are underfilled, as shown in Figure 5 for the 0.42 and $0.64 \mathrm{~cm}^{3} / \mathrm{g} \mathrm{DSC}$ scans. In contrast, when enough excess benzyl alcohol is present $\left(0.95 \mathrm{~cm}^{3} / \mathrm{g}\right)$ to wet the outside surface of the glass grains (Figure $1 \mathrm{~d}$ ), it is difficult to form a glass within the pores because nuclei readily form on the outside surface or interstitial spaces of the CPG powder during the cooling cycle and the crystallization propagates to the interior of the pores. Occasionally a glass is formed in the pores when the pores are overfilled, but in this case a crystallization exotherm (at $205 \mathrm{~K}$ ) of the pore liquid is always observed directly on heating after the glass transition event, as shown in Figure 5 for a degree of pore filling of $0.85 \mathrm{~cm}^{3} / \mathrm{g}$. For o-terphenyl, after the glass transition event has occurred, the liquid does not crystallize inside the $8.5 \mathrm{~nm}$ CPG despite the crystallization of the liquid on the exterior surface during the cooling cycle evidenced by the melting at 331 $\mathrm{K}$ for the bulk material (Figure 4). The liquid does not crystallize in the pores even when it sits for months at room temperature, well above $T_{g}$, even for pore diameters as large as $15.6 \mathrm{~nm}$. We consider some possible explanations for this behavior, including a difference in critical nucleus size between o-terphenyl and benzyl alcohol, the different wetting behavior and hydrogen bonding character for each compound and the effect of the large size and asymmetry of the o-terphenyl molecule on the crystallization kinetics.

One hypothesis for the resistance to crystal nucleation for liquids confined in pores is an increase in the value of $T_{b} / T_{m}$ for the liquid in the pores compared with the bulk. Because the vapor pressure is decreased in the pores due to the Kelvin effect (or capillary condensation), ${ }^{11} \mathrm{~T}_{\mathrm{b}}$ of the pore liquid is effectively increased, assuming that the slope of the vapor pressure versus temperature curve for the pore liquid is parallel to the curve for the bulk material. This coupled with the decrease in the melting temperature according to the Gibbs-Thomson equation (eq 1) increases the value of $T_{b} / T_{m}$ for all materials in CPGs. This effectively makes any organic liquid "less fragile" when formed at nanoscale sizes in CPGs and promotes glass formation for liquids that would normally crystallize. Although this hypothesis may explain why a glass forms more easily in small pores, it does not satisfactorily explain the difference in behavior between o-terphenyl and benzyl alcohol.
A second hypothesis for the resistance to crystal nucleation for o-terphenyl within the pores is that the critical nucleus size may be larger than the pore size. This was suggested recently for the glassification of lead in carbon tubes with a diameter of $2 \mathrm{~nm} .{ }^{78,79}$ Classical crystallization theory can be used to estimate the critical nucleus size, for a spherical nucleus of radius, $r_{c}$, according to the following relationship:

$$
r_{\mathrm{c}}=\left(2 \sigma_{\mathrm{sl}} \mathrm{T}^{*}\right) /\left(\Delta \mathrm{H}_{\mathrm{f}} \rho_{\mathrm{s}} \Delta \mathrm{T}\right)
$$

where $\sigma_{\mathrm{sl}}$ is the solid-liquid interfacial tension, $\mathbf{T}^{*}$ is the solid-liquid equilibrium (melting) temperature, $\Delta \mathrm{H}_{\mathrm{f}}$ is the bulk enthalpy of fusion, and $\Delta T=\left(T^{*}-T\right)$ is the degree of supercooling. ${ }^{80}$ For a wide range of substances, including organic melts, the critical nucleation temperature is between 0.8 and $0.85 \mathrm{~T} *$, although for hydrocarbons of longer chain length $(>15)$, it may approach $0.95 \mathrm{~T}^{*}$. Although eq 3 is derived for homogeneous crystallization of a spherical nucleus, it also applies to heterogeneous nucleation when the liquid does not wet the surface. In this case, the overall free energy of nucleation is the same as for homogeneous nucleation.

The critical nucleus size was calculated according to eq 3 , assuming that $\mathrm{T}^{*}$ is equal to the normal melting point and that the degree of supercooling is $0.85 T^{*}$. For o-terphenyl, a value of $r_{c}=3.1 \mathrm{~nm}$ is obtained using values of $\sigma_{\mathrm{sl}}=20 \mathrm{~mJ} / \mathrm{m}^{2}, 81 \Delta \mathrm{H}_{\mathrm{f}}=74.64 \mathrm{~J} / \mathrm{g}, \rho_{\mathrm{s}}=1.16$ $\mathrm{g} / \mathrm{cm}^{3}$, and $\mathrm{T}^{*}=329.3 \mathrm{~K} .{ }^{47}$ For benzyl alcohol, a somewhat smaller value of the critical nucleus size is obtained $\left(r_{c}=2.5 \mathrm{~nm}\right)$ for the same degree of supercooling $\left(0.85 \mathrm{~T}^{*}\right)$, with $\sigma_{\mathrm{sl}}=16 \mathrm{~mJ} / \mathrm{m}^{2}, 82 \Delta \mathrm{H}_{\mathrm{f}}=82.97 \mathrm{~J} / \mathrm{g}, \rho_{\mathrm{s}}$ $=1.0419 \mathrm{~g} / \mathrm{cm}^{3}$, and $\mathrm{T}^{*}=257.8 \mathrm{~K} .69$ The calculated values of the critical nucleus size may explain why crystal lization was never observed in the $4.0 \mathrm{~nm} \mathrm{CPG}$, since the value of $2 r_{c}$ is larger than the pore diameter. However, the calculated difference in the value of critical nucleus size is probably insufficient to explain the lack of crystallization of o-terphenyl in the $8.5 \mathrm{~nm}$ CPG material, compared to benzyl alcohol, when the pores are overfilled. For either material, the diameters of the crystalline nuclei are smaller than the pore diameter. At room temperature (298 K), the degree of supercooling is lower $\left(0.9 T^{*}\right), \Delta \mathrm{T}$ is reduced and the critical nucleus size increases to $r_{c}=4.4 \mathrm{~nm}$. This larger nucleus size is still insufficient to explain the lack of crystallization noted for o-terphenyl in the $15.6 \mathrm{~nm}$ diameter CPG, after annealing for over 2 months at room temperature. Thus, it appears the critical nucleus size alone does not control the solidification behavior of o-terphenyl in the porous glass.

A final consideration is the difference in wetting behavior and liquid character for o-terphenyl and benzyl

(78) Ajayan, P. M.; Iijima, S. Nature 1993, 361, 333.

(79) Prasad, R.; Lele, S. Philos. Mag. Lett. 1994, 70, 357.

(80) Mullin, J. W. Crystallization, 3rd ed.; Butterworth-Heinemann: London, 1993; Chapter 5.

(81) The solid-liquid interfacial tension, $\sigma_{\mathrm{sl}}$, can be estimated from the empirical relation, $\sigma_{\mathrm{M}, \mathrm{s}} / \Delta \mathrm{H}_{\mathrm{M}, \mathrm{f}}=0.33$, as given by: Dunning, W.J . In Physics and Chemistry of the Organic Solid State; Fox, D., Labes, M. M., Weissberger, A., Eds.; Interscience: New York, 1963; Chapter 7.

(82) For benzyl alcohol, a value for $\sigma_{\mathrm{sl}}=18 \mathrm{~mJ} / \mathrm{m}^{2}$ was calculated from the slope of a plot of $\Delta T_{m}$ versus $1 / d$ using the Gibbs-Thomson equation, as previously described. This value is in good agreement with the empirical value of $16 \mathrm{~mJ} / \mathrm{m}^{2}$ calculated using the method of Dunning. 
alcohol, since benzyl alcohol is able to form intermolecular hydrogen bonds. Kim and Karis ${ }^{83}$ have studied glass formation in low molecular weight organic melts to better understand how crystallization is suppressed by molecular properties such as hydrogen bonding and "interlocking" clusters whose structure precludes the orientation required for crystallization. In hydrogenbonding liquids, a strong "network" is formed between the molecules, and this property may explain why the exterior nuclei are able to propagate into the pores for benzyl al cohol. For o-terphenyl, however, only weak van der Waals bonding occurs and the network is less likely to support propagation of the crystalline nuclei. Alternatively, the large size and molecular asymmetry of the o-terphenyl molecule may simply hinder the kinetics of the crystallization process within the pores, compared to the benzyl alcohol. As previously noted, o-terphenyl is known to exhibit sluggish crystallization behavior in the bulk and this behavior may be accentuated in a confined geometry. Crystallization was observed readily in the largest pores studied $(d=73 \mathrm{~nm})$, where bulklike behavior was observed.

\section{Summary}

Confining a pure liquid to small pores changes the solidification behavior (glass formation and/or crystallization) in a fundamental way. The primary change seen in the glass transition behavior is that $T_{g}(d)$ is reduced relative to the bulk $T_{g}$ as a function of inverse pore diameter. An effort was made to estimate the breadth of the transition region of the pore liquid compared to the bulk liquid, by taking the difference between the midpoint and onset values of $T_{g}$. For o-terphenyl in the $8.5 \mathrm{~nm} \mathrm{CPG}$, a significantly broader transition region was measured by this method, but under similar conditions, benzyl alcohol did not show a broadened transition. Another significant result was that the shift in $T_{g}$ and the value of $\Delta C_{p}$ at $T_{g}$ for given pore size was independent of degree of pore filling. This suggests that the liquid forms "plugs" (Figure 1a) rather than wetting the interior surface of the glass as the liquid fills the pores. It is also consistent with our calculation that a reduction in bulk density or negative pressure effect is not large enough to cause the observed shifts in $\mathrm{T}_{\mathrm{g}}$. The downward shift in $\mathrm{T}_{\mathrm{g}}$ and the broadening of the transition region, observed experimentally, have features in common with finite-size effects pre dicted based on our understanding of both first- and second-order phase transitions, although quantitative comparisons are not yet possible.

The use of finite size effects to probe liquid behavior and study the competition between glass formation and crystallization is demonstrated to be a unique strategy to better understand a classical area of research. At

(83) Kim, S.-J .; Karis, T. E. J . Mater. Res. 1995, 10, 2128. small pore sizes $(4.0 \mathrm{~nm})$, crystallization is suppressed entirely even when nuclei are present outside the pores. This behavior is not surprising, however, since a calculation of the critical nucleus size for both o-terphenyl and benzyl alcohol yields a value larger than $4.0 \mathrm{~nm}$. When the pore size is slightly larger $(8.5 \mathrm{~nm})$, if there is excess liquid present the crystallization is controlled by the formation of exterior nuclei which propagate inward for benzyl alcohol. This behavior was seen only for benzyl alcohol, which forms a strong hydrogenbonded network, compared to o-terphenyl which was difficult to crystallize in the pores regardless of the degree of pore filling. In this case a combination of effects may be controlling the crystallization behavior, including sluggish crystallization kinetics for o-terphen$\mathrm{yl}$ and lack of hydrogen bonding in the liquid. Further studies on the kinetics of crystallization in confined geometries may be useful to better understand the experimental results.

The question of the ability to "pack" the molecules in the pores, especially when the pore diameters are only a few times larger than the size of the molecules, originally intrigued us in this work. This was especially true for the studies of the melting of crystalline organic materials in CPG's, ${ }^{13}$ where the unit cell has a very specific size and shape and must accommodate itself to the curved surface of the tubelike pore. Yet, we observed very close agreement with the continuum thermodynamics expressed by eq 1 . On the other hand, when one is considering liquids and glasses, the idea of discrete molecules packing inside the pores is less welldefined. It is difficult to address this question with the bulk calorimetric experiments described here, but we believe that future computer simulations or experiments of a different type, such as NMR, might offer insight into the approach to the molecular state as pore sizes decrease even further.

Acknowledgment. We thank S. S. Chang for providing us with the ultrapure o-terphenyl used in this study and for his hel pful comments on the glass-forming properties of this compound. W. Haller is gratefully acknowledged for providing us with the narrow pore size distribution CPG materials and for advising in the surface treatment. We acknowledge A. I. Nakatani and J . F. Douglas for many technical discussions and for encouragement during the course of this work.

Note added in proof: The glass transition temperature of free-standing polymer films as a function of film thickness has recently been reported using Brillouin light scattering. See: Forrest, J. A.; Dalnoki-Veress, K.; Dutcher, J. R.; Stevens, J. R. Am. Phys. Soc. Bull. 1996, 41, 617, and Phys. Rev. Lett., submitted.

CM 9601188 